\title{
Taevavõtmed ja kristusekäed - taimed lõunapoolse Kesk-Euroopa reformatsioonieelses kunstis ${ }^{1}$
}

\begin{abstract}
Ülle Sillasoo
Teesid: Lõunapoolse Kesk-Euroopa, samuti Madalmaade ja Itaalia 15. sajandi ja 16. sajandi alguse sakraalset kunsti iseloomustab taimekujutiste rohkus. Meistritest ja teemadest sõltuvalt võisid taimekujutised sarnaselt loomakujutistega täita pühapiltidel atribuutide, allegooriliste ja metafoorsete kujundite rolle ja/ või esindada maastikke. Taime välimus ja omadused, kasvukoht ja kasulikkus on aspektid, millest taimesümbolite retoorikas põhiliselt lähtutakse. Hiliskeskaegsetes ja varauusaegsetes rohuraamatutes ehk meie mõistes ravimtaimede käsiraamatutes leiduvad taimenimed võivad olla oluliseks võtmeks reformatsioonieelses kunstis kujutatud looduses kasvavate taimede tähenduse mõistmisel. Looduses kasvavate taimede kujutamise kaudu väljendub hilisgooti kunstis kristluse, rahvausu ja traditsioonilise argielu ühtekuuluvus. Siiski viis just rahvalike elementide rohkus ühe pilditraditsiooni katkemiseni usus ja kunstis ning asendumiseni teise, institutsionaalselt piiratud uue kujutamisviisiga.
\end{abstract}

Märksõnad: hilisgooti kunst, maastikud, reformatsioonieelne aeg, taimenimed, õistaimed

\section{Sissejuhatus}

Reformimeelsel Rooma katoliku kirikukogul, mis pidas ajavahemikus 15451563 kokku 25 istungit, enamiku neist Trento linnas, arutati esmakordselt ka religioossete teemade kujutamise küsimusi. 1563. aasta otsususega kutsuti üles igasuguse ebausu ja räpase luksuse eemaldamisele piltidelt ning iharuse kujutamisest hoidumisele (Waterworth 1848). 15. sajandi keskpaigaks oli laiemal hulgal varasemast paremale elujärjele jõudnud keskklassi esindajatel, sh õukonnafunktsionäridel, linnakodanikel ja Kesk-Euroopa lõunaosas ka maarahval, tekkinud võimalus ja vajadus ennast kunsti kaudu representeerida (Egg \& Pfaundler 1985: 7-10; Harbison 2002). See toimus avalikus sakraalruumis eksponeeritava altarimaali kaudu, kasutades rahvapäraselt demonstratiivset ja ekspressiivset väljendusviisi, mis avaldus eriti seoses pühakute ning Neitsi 
Maarja ja püha Anna kultusega. Piltide elavus ja elulähedus väljendus tugevates värvikombinatsioonides, joonistuste jõulisuses ja stseenide täiuslikkuses. Pildil toimuv toodi vaatajale lähedale kaasaegse riietuse ning realistlike, vahel õõvastavate detailidega märtrite piinamisest (Egg \& Pfaundler 1985: 7-10). Oma osa selles kristlik-teoloogiliste ideede ja dogmade kõrvale tekkinud rahvaliku usu väljenduses oli kunstnikel ja töökodadel, kellest mõned (näiteks Nürnbergi kunstnikud) seisid tellijale tunduvalt lähemal, olid sõltumatumad ja sotsiaalselt teadlikumad kui paljud konservatiivsemate koolkondade meistrid (vt Scribner 1994: 240; Scribner 2001: 64-65).

15. sajandi ja 16. sajandi alguse sakraalsele kunstile oli iseloomulik taimede sage ja täpne kujutamine, sh nii Madalmaade, Itaalia kui ka lõunapoolse KeskEuroopa kunstis (Behling 1967; Moggi 1987; Sillasoo 2006, 2009). Teaduse ja kunsti arengute kõrval, millega seda nähtust tavaliselt seletatakse (Moggi 1987), on rahvast ja tema suhtumist loodusesse ja religiooni siiski vähe käsitletud, selle mõistmine eeldab hiliskeskaja religioonietnograafia paremat tundmist (Scribner 2001: 85-103). Hiliskeskaja mõtlemisele olid omased sakramentalism ja maagia, üldlevinud uskumus üleloomuliku järjepidevasse olemasolusse materiaalses maailmas ning pühaduse ilmalik kogemine. Tavade, rituaalide ja pidustuste aeg ning iseloom sõltus suuresti looduskeskkonnast. Lõhnavad taimed ning vürtsid täitsid neis olulist osa, sh puhastust ja soosingut lubavate vahenditena (vt viiteid Scribner 2001: 55). Kõik loodu omas kaksipidist - argist ja religioosset - tähendust, teenides ühelt poolt keha heaolu, teisalt aga hinge lunastust. See, mis allus inimese viie meele kaudu toimivale tajule, oli osa reaalsuse sümbolite ja sümboolse reaalsuse komplekssest semiootilisest süsteemist (Scribner 2001; vt ka Huizinga 1996 [1924]).

Sõltuvalt meistritest ja teemadest võisid hiliskeskaja ja varase uusaja kunsti taimekujutised, just nagu loomakujutisedki, esineda pühapiltidel atribuutidena, allegooriliste ja metafoorsete kujunditena ja/või loodusmaastikele iseloomulike elementidena (vt Behling 1967; Cohen 2008). Siiski, kui loomakujutiste valik sõltus paljuski bestiaariumite ${ }^{2}$ traditsioonist (vt Cohen 2008), välja arvatud ehk mõned kultuurtaimedest erandid, oli kunstniku käsutuses kogu lähikonnas kasvav taimestik. Religioossete tekstide, sealhulgas piibli taimemetafoorid ja -allegooriad on botaaniliselt raskesti määratletavad ja nende pildilised tõlgendused sõltuvad kultuuritraditsioonist. Esimese Moosese raamatu hea ja kurja tundmise puud (1 Ms 2:9, 2:17) võib kultuurilisest ja looduslikust keskkonnast lähtuvalt tõlgendada viigipuu, viinapuu, granaatõunapuu või õunapuuna. Samuti võib selleks olla kuivanud puu, erinevalt rohelisi lehti kandvast igavese elu puust (vt Réau 1996; Kirschbaum 1994). Kristlikud rahvalikud jutlustajad, sealhulgas frantsiskaan Berthold von Regensburg (1220-1272), kelle silmis loo- 
dus ja jumalasõna olid võrdväärsed, kasutasid taimi ja loomi kui didaktilisi vahendeid (exemplae) doktriinsete või moraliseerivate teemade illustreerimiseks, et muuta need mõistetavaks nii vaimulikule kui ka ilmalikule kuulajaskonnale ning erinevate ühiskonnakihtide esindajatele (Pfeiffer 1862-1880; Reinitzer 1982; Cohen 2008). Teoloogilise ettevalmistusega autorite hiliskeskaegsetes loodusloolistes teostes on looduslike objektide kirjeldused põimitud jumalasõnaga. Konrad von Megenbergi (1309-1374) Looduse raamatus (Das Buch der Natur, ca 1349-1350) viitavad võililled (Taraxacum officinale; Marzell 1943-1979) ehk lilled väljal ja oliivipuu Neitsi Maarjale, kelle piiritu heatahtlikkus ja lahkus on nagu palsam haigele hingele, kõrvits on aga öise õitsemise tõttu patustajate sümbol (Pfeiffer 1861: 412, 335-336, 393). Sellised hiliskeskaegsed võrdlused on sageli aja- ja kohapõhised ning sotsiaalselt määratletud, kuid nende juured võivad ulatuda ka vanemasse traditsiooni. Neis avalduvad hea ja halva, Jumala ja Saatana või imaginaarsete paradiisi ja põrgu vastandused on äratuntavad ka kristliku kunsti looduskäsitluses.

Käesoleva artikli eesmärk on arutleda valitud näidete varal, milline võis olla taimemotiivide tähendus 15 . sajandi ja 16. sajandi alguse Kesk-Euroopa lõunapoolse osa (saksa kultuuriruumi) sakraalses kunstis, mis ühtlasi iseloomustab reformatsiooni eel valitsenud mentaliteeti. Tähelepanu keskmes on pühapiltidel kujutatud taustamaastikud teede, hukkamispaikade, tarade ja inimasustuse juures kujutatud taimedega. Need pildid moodustasid veidi enam kui kolmandiku artikli autori poolt analüüsitud taimi kujutavatest ligikaudu 250 hiliskeskaegsest religioosse sisuga tahvelmaalist (Sillasoo 2003, 2006, 2009). Uurimistöös kasutati ikonograafilisest, fenomenoloogilisest ja antropoloogilisest meetodist kombineeritud lähenemist (vt Burke 2008; Scribner 1994) ning otsiti (sajandite taguseid teadmisi silmas pidades) vastuseid küsimusele, mis tahvelmaalidel kujutatud taimi nähes esmalt tekib: "Mis see on?". Lisaks arheoloogilisest materjalist seni leidmata looduslike liikide ja kultuurtaimede varieteetidele (vt ka Sillasoo 2006; Janick \& Paris et al. 2007; Gago \& Santiago et al. 2009; Paris \& Janick et al. 2011) avaldub sedalaadi allikmaterjalis taimede kultuuriliste kontekstide ja taimedesse suhtumise mitmekesisus ajaloolises plaanis.

\section{Põhilised kujutamis- ja tähendusmallid}

Maastiku ja selle elementide kujutamise hiliskeskaegsetel pühapiltidel tingib osaliselt religioosne narratiiv. Tee on oluline maastikuline element loos püha perekonna põgenemisest Egiptusesse, varakristlike märtrite tagakiusamise ja 
põgenemise lugudes, lugudes Neitsi Maarja külaskäigust Eliisabeti juurde ning Kristuse ristikandmisest. Aiad ja hoovid raamivad stseene Jeesusest Õlimäel ehk Ketsemani aias, aga ka Maarja külaskäiku Eliisabeti juurde. Loodusmaastikud on valdavad pühakute märtrisurma ja Kristuse ristilöömise stseenides. Suurem osa vaadeldud piltide teemadest pärines piiblist ja keskaegsetest pühakulegendidest (Voragine 1993), kuid leidus ka ikoonitaolisi maale. Neitsi Maarja elu kujutati vähem kui veerandil maastikutaustaga maalidest, sh stseenid Maarja külaskäigust Eliisabeti juurde, püha perekonna põgenemisest Egiptusesse, Jeesuse sünnist ja tarkade külaskäigust. Taimedel, mida kujutati maastikuliste elementide juurde kuuluvana, võis olla nii keskkonda iseloomustav kui ka sisuline ülesanne (erineva retoorilise rõhuga sümbolid ja metafoorid).

Kultuurtaimed on loodusmaastikes kõige selgemad rõhutatud sümbolid, sest esinevad niiöelda vales kontekstis. Loodusmaastike taustal kujutatud looduslike taimede tõlgendamine sümbolitena on keerulisem, kuid mitte võimatu, ning siin tasub jälgida taimekujutiste esinemissagedust ja temaatilisi kontekste. 15. ja 16. sajandi kunstnike praktiseeritud naturalism muutis objektid nende kontekstilise paigutuse tõttu vähem ilmseteks ehk hajutatud sümboliteks, mille tähendus pidi selguma alles stseeni üle pikemalt mõtiskledes (Panofsky 1971; Ward 1994).

Teeäärsete ja loodusmaastike kujutamisel näiteks Jeesuse kannatuse ja pühakute märtristseenides olid valdavad looduses kasvavad taimed. Maikellukest (Convallaria majalis L.), mis esines maalidel kõige sagedamini, kujutati sümbolina enamasti üksikult ja esiplaanil, kuid näiteks stseenis püha Cantiuse, Cantianuse ja Cantianilla põgenemisest ( ca 1510, Krainburgi altari meister, Stüüria; nr 000693 Kremsi digitaalses andmebaasis, http://tethys. imareal.sbg.ac.at/realonline/) paiknesid need hajusa kogumikuna teeäärsel nõlval. Sotsiaalse alatoonita maikelluke sulandub hästi loodusmaastikulisse tausta, kuid tema asetus pildiruumis ja kontekstist sõltumatu esinemissagedus (vt ka Sillasoo 2009) viitavad rõhutatud sümbolismile. Taimede valge värv, intensiivne lõhn ning võib-olla ka mürgisus on omadused, mis nii nagu valge liiliagi puhul sobisid arusaamaga pühadusest (ja surmast). Kuldses legendis (Voragine 1993) mainitakse meeldivat lõhna pühakuid iseloomustava tunnusena näiteks püha Dominicuse ja Maarja Magdaleena lugudes; püha Dominicust kujutatakse kunstis, käes valge liilia.

Taimede värvi- ja lõhnaomadused on hiliskeskaegses sakraalses sümboolikas sageli määravad. Ühel Slovakkiast pärit altarimaalil kujutatakse Jeesuse ristilöömise stseenis (enne 1500. aastat, tundmatu meister; $\mathrm{nr}$ 011683) risti all vaniljelõhnalist orhideed (Nigritella nigra (L.) Rchb. f. agg.). Selle taime rahvapärased nimed 'verirohi' ja 'veriroos' Tiroolis (Blutkraut, Blutrösl), 'verepiisake' 
Alam-Austrias (Blutströpfel) ja 'verinelk' Kärntenis (Blootnagel) (Hegi 1922) tulenevad õite erkpunasest värvist. Hiliskeskaegsetel roosikrantsi kujutistel (Winston-Allen 1998) on punane Jeesuse kannatuse ja vere värv (vt ka Marzell 1960). Šoti altari risti kandmise stseenis (1469/80, Šoti altari meister, Viin; $\mathrm{nr}$ 000302; pilt $1 \mathrm{a}$ ja b) esindab Jeesuse kannatuse kontseptsiooni isegi terve
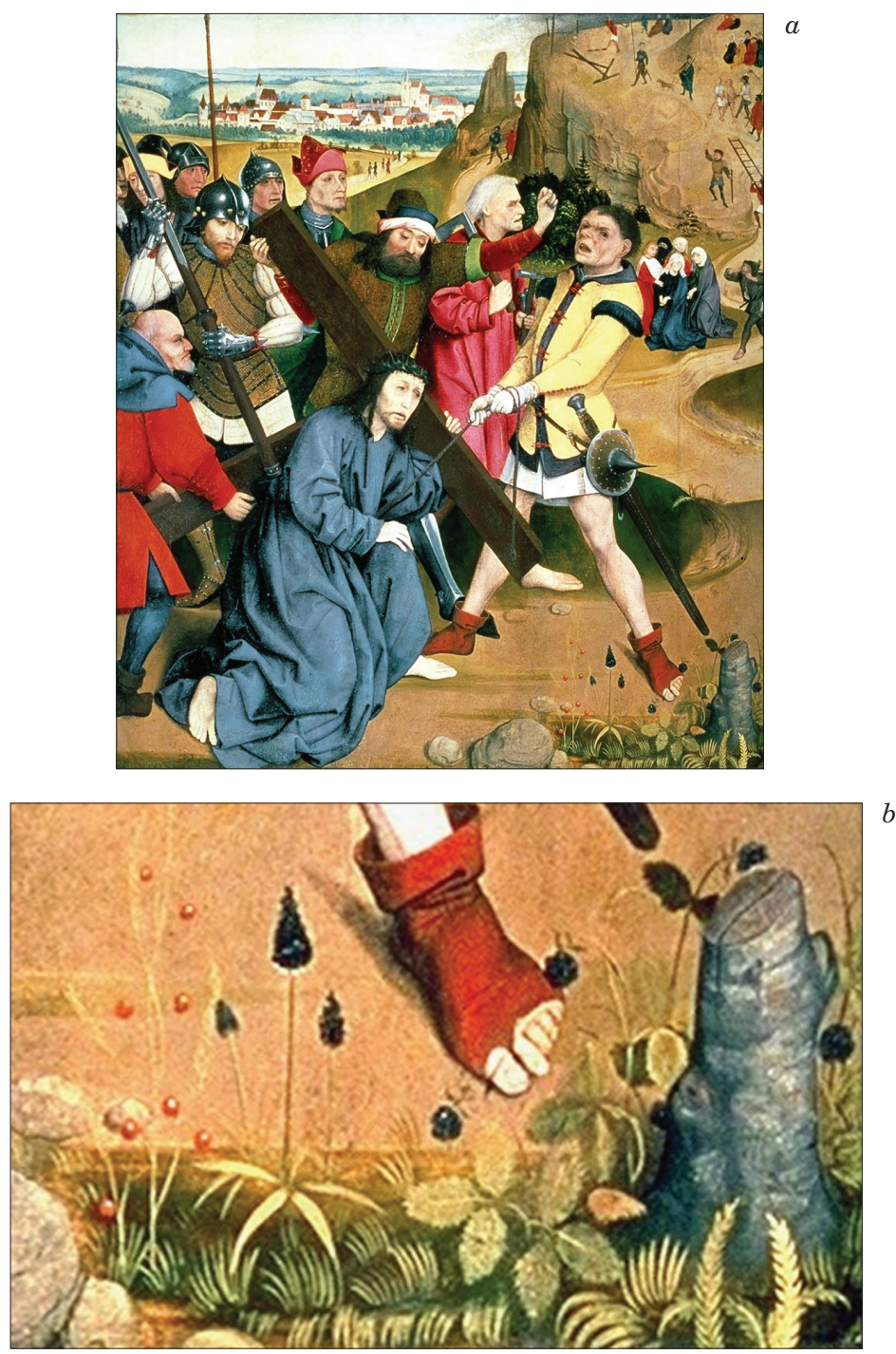

Pilt 1. a- "Risti kandmine", 1469-80, Šoti altari meister, Viin (digitaalses andmebaasis nr 000302); b - fragment taimedega: harilik aspar, kobarhüatsint, metsmaasikas, põldmurakas. 
ansambel looduslikest ja aias kasvavatest kevadel õisi ja suve lõpul vilju kandvatest taimedest: kobarhüatsint (Muscari cf. botryoides (L.) Mill.), põldmurakas (Rubus caesius L.), harilik aspar (Asparagus officinalis L.) ning maasika lehtede ja punase ristiku õiega taim, mida ei ole võimalik botaaniliselt määrata. Kobarhüatsindi ja põldmarja viinamarjakobarat meenutav (vastavalt) sinine õisik ja koguvili (mari); põldmarja veinpunane mahl ja Kristuse krooniga assotsieeruv okkaline võsu ning aspari veripunased marjad liidavad need taimed Kristuse kannatuse sümboliteks. Ka (siin ambivalentse) maasika kujutis on religioossetel maalidel sageliesinev sümbol, ilmselt värvi- ja vormiomaduste tõttu: Neitsi Maarja on see õis ja see (paradiisi)aed, milles vilja ja viljakandva puuna kasvab Jeesuslaps (Salzer 1893), valge tähistamas puhtust ja punane kannatust ning kolmetine leht, mida esineb teistelgi taimedel peale maasika, sh ristikud ja jänesekapsas, kolmainsust. Maasikat kui paradiisiaia sümbolit kujutatakse juba meister Bertram von Mindeni Graboweri altaritahvlil "Maailma loomise 4. päev" (1375-1383, Hamburger Kunsthalle), Ülem-Rheini meistri maalil "Paradiisiaiake" (ca 1410, Städel Museum, Frankfurt), aga ka Albrecht Düreri maalil "Neitsi ja Jeesuslaps võlvkäigu ees" (Bagnacavallo Madonna; enne 1505, Magnani-Rocca Fond, Traversetolo, Itaalia).

Taim võib olla sümbol liigilisel ja/või üldisemal tasandil. Taimekujutist võib mõista ka kui tüübilist 'roosi' või 'liiliat', nt aed-tokkroosi (Alcea rosea L.), mis on esiplaanil maastikulises stseenis "Põgenemine Egiptusse" (ca 1469-80, Šoti altari meister, Viin; nr 000306; pilt 2 a ja b), või oma ajas haruldast kollast püvilille (Fritillaria imperialis L. var. lutea) stseenis "Maarja külaskäik Elisabethi juurde" (1524, Andreas Haller, Lõuna-Tirool; nr 002023). Kollast püvilille mainitakse kirjalikes allikates esmakordselt 16. sajandi keskel (Krausch 2007). Esimeses stseenis moodustab kompositsioon tokkroosist, allikast ja linnust (rasvatihane, Parus major L.) paradiisliku vaikelu, mida võiks tõlgendada püha perekonna põgenemise ja pääsemise sihtkohana. Mõlemas stseenis annab aiataimede kasutamine alust seostele paradiisiaiaga. Võõramaist päritolu ja kõrgemat sotsiaalset kuuluvust markeerivatel kultuurtaimedel on siin ka autoreid, teemas esinevat mobiilsust ja maali pidulikkust esindav ülesanne (vt Koch 1964; Sillasoo 2009). 


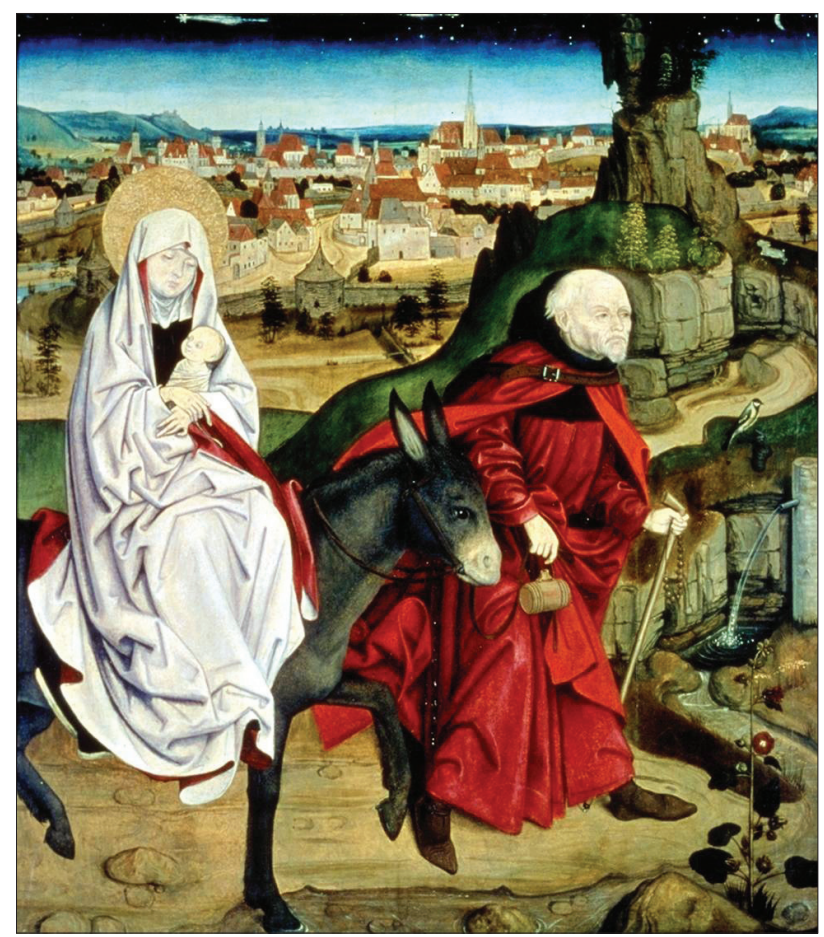

$a$

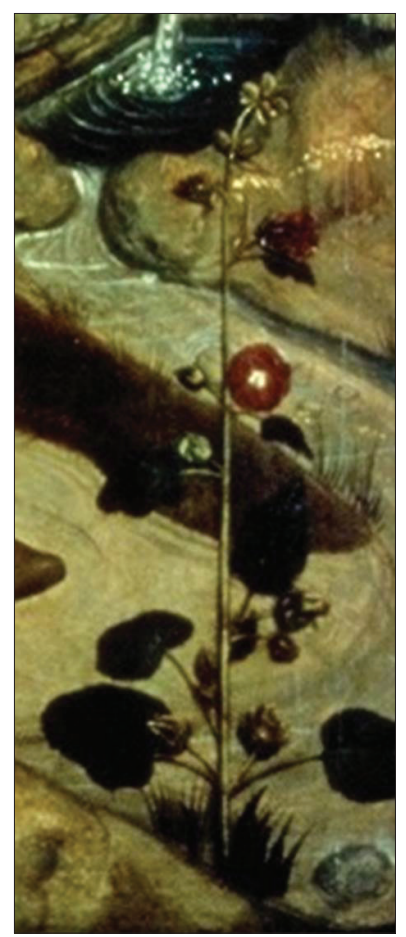

$b$

Pilt 2. a - "Põgenemine Egiptusse", ca. 1469-80, Šoti altari meister, Viin (000306); b - fragment aed-tokkroosiga.

\section{Taimenimed kui tähenduse kandjad}

Paljud hilisemad rahvapärased taimenimed sisaldavad võrdlusi Kristuse kannatuse (verega värvunud) atribuutidega, nt naelad (nelk), oda (hundinui), okaskroon (ohakad ja kibuvits); tumedad laigud lehtedel tulenevad verest, mis langes risti all kasvanud taimedele (orhideed), või tekkisid sinna pühakute, nt püha Johannese märtrisurma päeval (naistepuna) (Marzell 1960). Üheks mooduseks looduse ja kultuuri (religiooni) vaheliste hiliskeskaegsete seoste ja taimekujutiste tähenduse tundmaõppimisel on lehitseda tolleaegseid rohuraamatuid ja jälgida taimenimede erinevaid kujusid. Varauusaja rohuraamatute teoloogidest autorid seletavad taimede nimesid mitmeti. Näiteks nimetatakse 
härjasilma (Leucanthemum vulgare Lam.) püha Johannese lilleks (Johansblomen, Sant Johansbli̊men), sest ta ilmub (õitseb) jaanipäeva paiku (Marzell 1943-1979, Chrysanthemum leucanthemum: 964). Neitsi Maarja järgi on nime saanud Maarja taevaminemispüha ajal (15. august) õitsevad taimed, näiteks keelikurohi (Carlina vulgaris L.) (Frawendistel); nende õnnistamine sellel pühal võimendas raviomadusi ja väge kurjade jõudude vastu (Marzell 1965). Botaanilis-meditsiinilises kirjanduses ongi kõige rohkem Neitsi Maarja ja püha Johannese järgi nimetatud taimi (Bauhin 1591). Varauusaegsed rohuraamatud olid vastavalt linnades ja oukonnas kehtestatud nõuetele enamasti mõeldud apteekritele. Oli keelatud koguda teadmisi taimede raviomaduste kohta kirjaoskamatutelt floristidelt, herbalistidelt ja vanadelt naistelt (Reeds 1991). Viimaseid kirjeldatakse kummaliste rituaalide läbiviijatena; kristlike taimenimedega kõrvuti mainitakse (maagilisi) mittekristlikke nimesid, nt 'paljad neitsijuuksed' vrs 'tee tagasi' (nacket Jungfraw hor vrs Widderthon; harilik karusammal (Polytrichum commune Hedw.); Marzell 1943-1979, P. commune: 963, 965-967). Nähtavasti olid rohuraamatute autorid (ülikoolides taimi ja nende omadusi õpetavad teoloogid) kristlike nimede peamised propageerijad, sest nad pidasid ravimist jumala asjaks. Rahvaravitsejatel tõenäoliselt puudus otsene vajadus taimi nimetada, piisas teadmisest, kuidas neid kasutada.

Uuritud maalide ülestõusmispühade tsükli stseenides olid olulisel kohal nurmenuku (Primula veris L.) kujutised. Šoti altari Kristuse ristilöömise ja lamentatsiooni stseenides (1469-80, Šoti altari meister, Viin, vastavalt nr 000301 (pilt 3 a ja b) ja 000707) on nurmenukk ainus või üks vähestest kujutatud taimedest, mis täidab rõhutatud sümboli ja metafoori rolli. Sellist kujundikasutust võib näha Hofi altari Kristuse ristilöömise stseenis (1465; Munich Alte Pinakothek), mille maalis Nürnbergis tegutsenud Hans Pleydenwurff ja mille järgi on maalitud Šoti altari vastav tahvel (Vavra 1980). Nurmenuku rõhutatud sümbolism on arvatavasti seotud tema õitsemisega kevadel ülestõusmispühade ajal. Hiliskeskaegses saksa kultuuriruumis nimetati nurmenukku muuhulgas 'taevavõti', 'võtmelill', 'peetrivõti'3 ja 'paastulill' (himmelschlüssel, slusselblomen, Peter Schlüssel Vastenblumen; Marzell 1943-1979, P. veris: 1052-1082; Fischer 1929). Seni selgusetu päritoluga legendi kohaselt olevat võtmekimpu meenutava õisikuga taim tärganud kohast, kuhu Peetrus pillas taevavõtmed (Marzell 1943-1979, P. veris: 1057; vt ka Bächtold-Stäubli \& Hoffmann-Krayer 1987). Nurmenuku taevaliku valguse ja ülenduse kuldsed või kollased õied (vt Himmel, Kirschbaum 1994; Wackernagel 1872) tähistasid kannatusstseenide kontekstis Jeesuse surma ja ülestõusmist. 


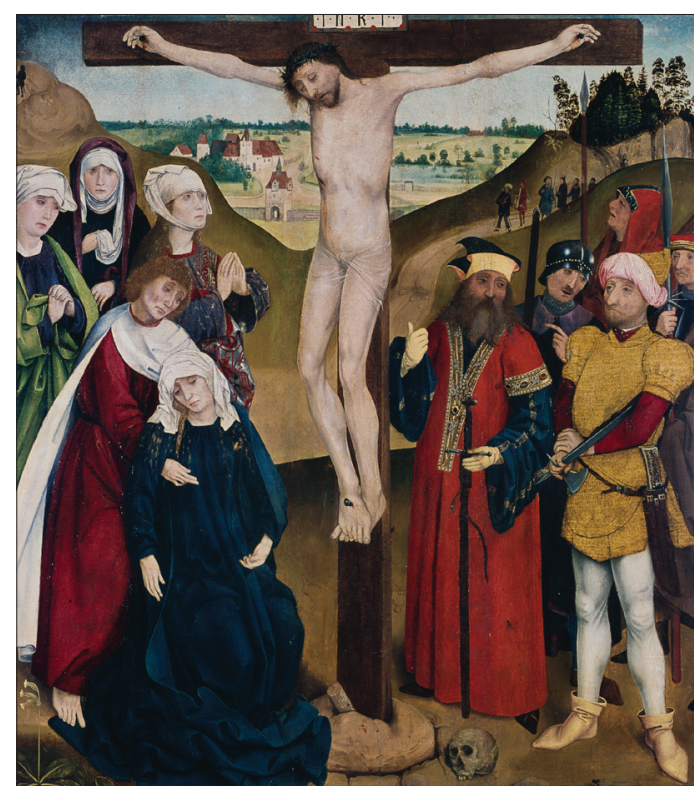

$a$

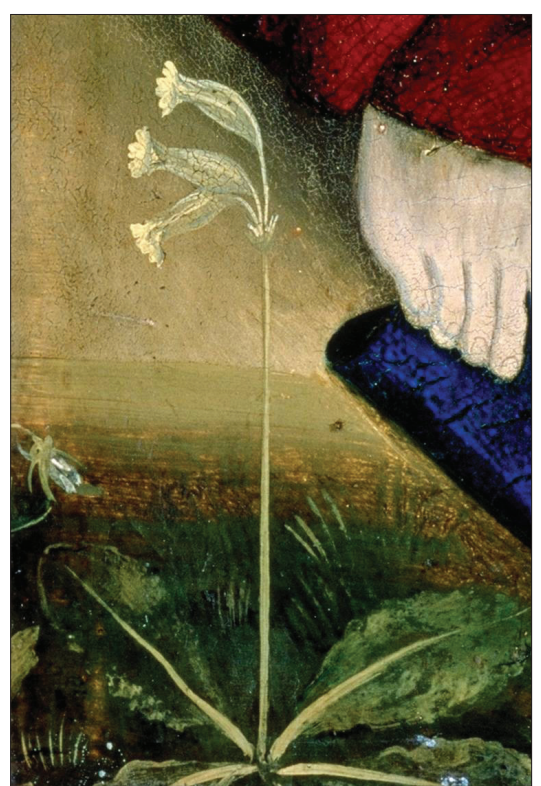

$b$

Pilt 3. a - "Kristuse ristilöömine", 1469--80, Šoti altari meister,Viin (000301); b - fragment nurmenukuga.

Taevavõtmeteks nimetati hiliskeskajal teisigi kevadel õitsevaid taimi, sealhulgas võilille (Konrad von Megenberg, vt eespool) ja orhideesid. Ka neid kujutatakse sarnaselt nurmenukuga pühakute kannatuse ja Kristuse ristilöömise stseenides. Maalil püha Valentini martüüriumist (1505, tundmatu meister, Lõuna-Tiroolia, nr 002763) on näiteks laialehise sõrmkäpa kujutis (Dactylorhiza majalis (Rchb.) P. F. Hunt et Summerh.). Stseenis püha Liberiuse elust (ca 1480, tundmatu autor, Moraavia; nr 013008; pilt 4 a ja b) on teeäärse maastiku 'taevavõtmeks' kahvatu käpp (Orchis pallens L.), mida Tiroolist pärit benediktiini munk Vitus Auslasser on nimetanud primula veris alba (Mayer \& Goehl et al. 2009). Vitus Auslasser on teadaolevalt esimene hiliskeskaegne autor, kes eristab orhideeliike (värvi alusel). Orhideede teised teadaolevad keskaegsed ja varauusaegsed nimed, mis samuti õigustavad taimede kujutamist religioossetes stseenides - 'Kristuse käe taim', 'käejuur', 'ristipuu' ja 'ristilill' (planta vel palma Christi, Hendelwurtzel; cruz bowm, Crützblumen; Fischer 1929: 276; Marzell 1943-1979, Orchis: 419-444) -, tulenevad taimede juurestiku morfoloogiast, mis meenutab inimese kätt, ja õitsemise ajast. Saksa varauusaegne botaanik Otto Brunfels (ca 1488-1534) selgitab, et taime nimetatakse Kristuse käeks sellepärast, et selle kaks juurt asetsevad teineteise peal nagu kaks kätt 


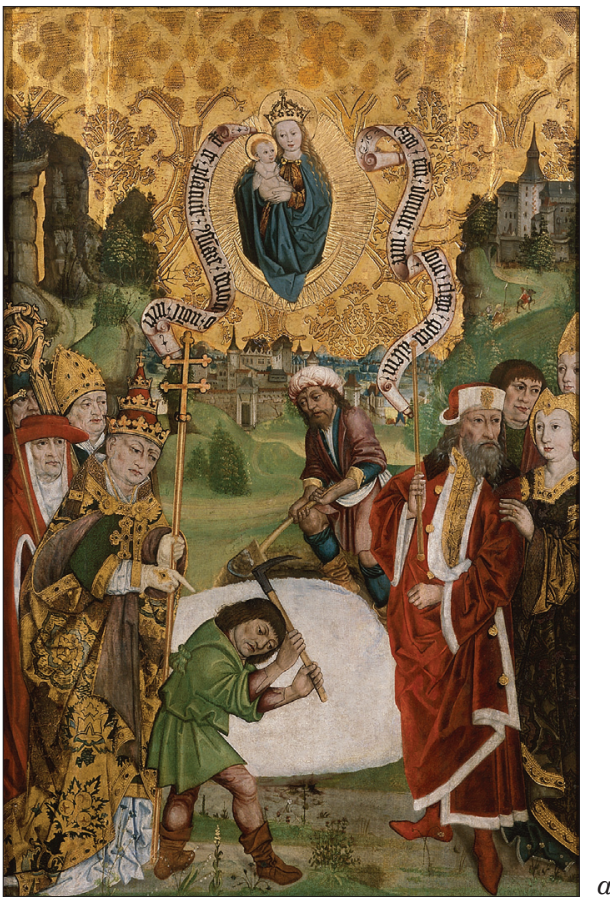

Pilt 4. a-stseen püha Liberiuse elust (lumeime), ca 1480, tundmatu autor, Moraavia (013008), b-fragment taimedega: rukkilill, maikelluke, kahvatu käpp, väike igihali, metsmaasikas, jumikas (?).

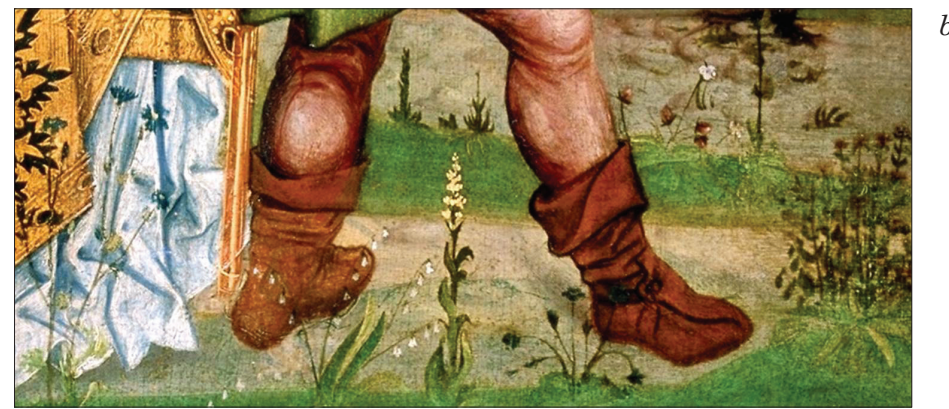

(Das weiblin hat zwo wurtzel uffeinanderliegen gleich zwey henden, derhalben Palma Christi genannt); Hieronymus Brunschwyg'i (ca 1450 - ca 1512) kohaselt kutsutakse seda aga ristililleks sellepärast, et taim kannab õisi risti- ehk ülestõusmisnädalal (...darum das sin gewechss die blumen in der crütz wochen bringen sin; Marzell 1943-1979, Orchis: 423, 436). Ka eespool mainitud vaniljelõhnalise orhidee Nigritella varasemate (enne 1671) nimede seas on 'väike Kristuse käsi' (palma Christi minor; Marzell 1943-1979, N. nigra: 327-334). Õitsemise ajaks areneb neil orhideedel kaks juuremugulat, millest vanemat ja tumedamat seostati kuradi käega, uuemat ja heledamat aga jumala, Kristuse või Maarja käega (Vorfrues finger; Marzell 1943-1979, Orchis: 425). Laialehise 
sõrmkäpa lehtedel olevad pruunikad laigud ja täpid on inspireerinud nime 'Maarja pisarad' (Märgendrehen, Unser Frawen Trähen; Marzell 1943-1979, Orchis: 431-432); rahvaluules peetakse neid vereplekkideks ja märgitakse, et sellised taimed olevat kasvanud Kristuse risti all (Marzell 1960).

Mitmed hiliskeskaegsed altarimaalid ja hilisemad reformatsioonipropagandat sisaldavad pildilised trükised on tõestanud kuraditeema populaarsust (vt Koch 1964; Russell 1992; Scribner 1994). Kuradinimelised taimed võisid metafooride ja allegooriatena osaleda stseenides vastandlikel põhjustel. Sellistel taimedel usuti olevat tõrjemaagiline vägi või oli taime välimus ja kasvuviis võrreldav ettekujutusega saatanast (Marzell 1955, 1962). Steiermargi liidumaalt pärit Kristuse ristikandmise stseenis (1505, tundmatu meister; nr 000790) ja ühes täpsemalt määratlemata päritoluga Kristuse ristilöömise stseenis (enne 1500, Ülem-Austria/Nürnberg; nr 000433) kujutatakse küüniseid meenutavatesse õisikutesse koondunud õitega kerarapuntslit (Phyteuma orbiculare L.), tänapäeval rahvapäraselt kuradiküünt (Teufelskralle; Hegi 1922; Marzell 1955). See nimi võis olla kasutusel juba keskajal, kui mõelda õie välimusele ja vastava metafoori sobivusele kannatust käsitlevasse pilditeemasse. Esimesel pildil on taim kõrvuti kirju sarikhernega (Securigera varia (L.) Lassen) - roosade õitega liblikõielise taimega, millel on tumepunased teravatipulised kõverdunud küüniseid meenutavad kaunad. Taime keskaegne nimi ei ole teada. Teisel pildil on kerarapuntsel kõrvuti kristlikus sümboolikas laiemalt levinud maikellukese ja metsmaasikaga ning taimega, millel on hariliku käbiheina (Prunella vulgaris L.) lehed ja munaja rapuntsli (Phyteuma ovatum Honck.) õisiku sarnane punaste ogaliste tupplehtedega õisik. Selline ebamäärane kujutamisviis võib tähendada seda, et maaliti mälu ja/või kirjelduse järgi. Taimi kujutati kuulduste järgi isegi rohuraamatutes (vt Arber 1912, seoses rohuraamatuga Gart der Gesundheit). Taime keskaegne nimi Brunelle võis tuleneda pruunikast õiekattest, ploomikarva õitest või siis hingamisteede haigusest Bräune, mille ravimiseks taime kasutati; nimega võidi tähistada mitmeid kirjeldusele vastavaid taimi. Sisemiste ja välimiste haavade raviga arvatakse olevat seotud käbiheina hiliskeskaegsed ja varauusaegsed nimed 'jumalarohi' ja 'püha Antoniuse rohi' (Gotheil, St Antoniuskraut; Marzell 1943-1979, P. vulgaris: 1085-1091). Haavadega assotsieeruvaid taimi ja seeni on kannatusstseenides kujutatud teistelgi juhtudel.

Võilill (Taraxacum officinale F.H.Wigg. s.l.), mille paljude keskaegsete nimede hulgas leidub ka 'kuradirohi' (Teüfelskraut; Fischer 1929; Marzell 1943-1979, T. officinale: 618), esineb keskaegses kunstis sageli. Realistlikke võilille kujutisi võib näha juba 14. sajandi alguse maalidel (Moggi 1987). Uuritud maalidel kujutati võilille esmajoones maastikel, kuhu kunstnik paigutas Kristuse kannatusloo ning stseenides pühakute elust (vt Sillasoo 2003, 2006). Nimi 'kuradirohi' 
võib osutada taimele kui tülikale umbrohule või selle mõrkjale piimmahlale (Marzell 1943-1979, T. officinale: 618). Rahvausus liigituvadki umbrohud halbade ehk kuraditaimede hulka. Hiliskeskaegsest arheobotaanilisest materjalist võilille palju leitud ei ole, kuid taime sage kujutamine kunstis (Moggi 1987; Sillasoo 2006) ja nimede mitmekesisus (Marzell 1943-1979, T. officinale: 601-602) võivad siiski tähendada tema olulisust toonastes kultuurmaastikes. Nimed 'metsik heliotroop', 'aiavalvur' ja 'väljalill' (eliotropia agreste, solsequium agreste, custos ortorum, veltpluomen; Fischer 1929: 286; Marzell 1943-1979, T. officinale: $601,618,622$ ) viitavad sellele, et võilill kasvas spontaanselt aias ja põllul (väljal); piltidel kujutatakse võilille ka teeservades. Lai nimedevalik annab võimaluse erinevateks assotsiatsioonideks ja tõlgendusteks. Taime morfoloogiale ja õitsemise ajale viitavad 'märtsilill', 'suveohakas', 'kollane päikeseratas', 'Iõvihammas', 'Iõvilill' (merzenblumen, Summerdorn, Gelb Sonnenwyrbel, lewenzan, planta leonis); 'papileht', 'papirohi', 'papitoruke' ja 'mungapeake' on võrdlused seemned kaotanud õiepõhja ja munga palja pealae vahel (Pfaffenblatt, Pfaffenkraut, Pfaffenrörlin, Münchsköpflin; Marzell 1943-1979, T. officinale: 600-655). Nime 'lõvihammas/hambad' saab seostada loomasümbolismiga: lõvil, keda kujutatakse märtrite surma ja Kristuse ristilöömise stseenides, on patust ja surmast päästja tähendus (vt Löwe, Kirschbaum 1994; vt ka Cohen 2008). Tähenduslik võis olla ka võililleõite kollane värv (vt nurmenukk, eespool).

Kuldkollaste õitega tulikat (Ranunculus cf. acris L.) kujutati uuritud maalidel üksikutes pühakute märtristseenides. Püha Andrease ristilöömise stseenis (15. sajandi teine pool, tundmatu meister, Alam-Austria; nr 001649) on tulikas ainuke taim risti kõrval. Püha Bartolomeuse märterluse stseenis (enne 1500. aastat, tundmatu meister, Alam-Austria; nr 000751) kasvavad piinapingi lähedal peale tulika veel kurekell (Aquilegia vulgaris L.) ja maikelluke. Maikellukese tähendust selgitati eespool. Kurekella tunti väidetavalt rohkem aia- kui metsataimena (Krausch 2007; Sillasoo 2009). Tema laiemalt levinud sümbolism tulenes õiest, mille kroonlehed sarnanevad viiele külg külje kõrval asetsevale tuvile, andes taimele vagaduse, püha vaimu ja jumala kutse tähenduse (vt Akelei, Kirschbaum 1994; Löber 1988; Koch 1964; vt ka tuvi sümbolismi, Cohen 2008). Seda, et tulikat tunti ja teati looduses hästi, tõendavad nimed ja ülestähendused rohuraamatutes (Fischer 1929; Marzell 1943-1979, Ranunculus: 1220-1285). Üks osa nimedest annab edasi taime morfoloogilisi tunnuseid, sh lehe kuju, mis sarnaneb linnu jalgadele: 'kanajalg', 'kanajäljed', 'kurejalad' ja 'kaarnajalad' (hanenfuz, hanenwurz, hannsporen, chreanfueß, rabenfue $\beta$; Fischer 1929; Marzell 1943-1979, R. acris: 1221); teine osa nimedest peegeldab taime omadusi, sh püha Antoniuse naeris (rapa di S. Antonio; 
mugultulikas (R. bulbosus L.), Fischer 1929) ja põletusrohi (brenkrut; Marzell 1943-1979, R. acris: 1230). Värskete tulikate mahl võib nahale sattudes tekitada kipitust, punakaid laike ja ville. Tirooli päritolu benediktiini munk Vitus Auslasser kasutab seevastu taime kuldkollaseid õisi rõhutavat nime ‘õnnistatud safranikollane' (benedicta crocea, villtulikas (R. languinosus L.), Mayer ja Goehl et al. 2009). Õitele viitab ka 'läiklill' (Glitzenpluem; Mayer ja Goehl et al. 2009; Fisher 1929; Marzell 1943-1979, R. acris: 1227-1228). Arvatavasti oli tulikas altarimaalidel valu ja kannatuse ning taeva kuldse sära allegooria. Vitus Auslasseri rohuraamatus kasutatud nimevarianti võidi tõlgendada ka itaaliapäraselt ‘õnnistatud ristina' (benedetta croce), mis selgitaks ja õigustaks veelgi tulika kujutamist püha risti kõrval.

Teeäärseid maastikke kaunistab mitmel juhul harilik sigur (Cichorium intybus L.). Keskaegsed nimed 'teeääres ootaja' või 'teenäitaja' (wegewarthe, wegwart, Wegwartbluem, Wegwysz or Wegweiß; Marzell 1943-1979, C. intybus: 990-998) lähtuvad taime reaalsest kasvukohast, sobides ühtlasi metafoorideks varakristlike pühakute märtrisurma ja muude teedrajava sisuga stseenidesse. Hariliku siguri metafoori kasutatakse näiteks stseenis Maarja külaskäik Eliisabeti juurde, kus saavad kokku kaks lapseootel naist (enne aastat 1500, tundmatu meister, Viin; nr 000414; pilt 5 a ja b); siguri õied ja neitsi Maarja mantel on mõlemad sinised. Taime heliotroopsetele omadustele viitavad nimed 'päikeserohi' ja 'päikese sinine ratas' (Sonnenkraut, Sunrayd, Sunnenwerbel, Blaw sonnenwyrbel; Marzell 1943-1979, C. intybus: 990-998) on neitsi Maarjat iseloomustavate võrdlustena samuti omal kohal. Musta vägiheina (Verbascum thapsus L.) rolli mainitud pildil aitavad seletada taime välimuse ja kasutusega seostuvad nimed 'küünal', 'kuningaküünal', 'küünlarohi', 'väljaküünal' ja 'taevatuli' (saksa k. candela, luminaria, cuniges kerze, kertzenkraut, Feldtkerzen, himmelprant), valguse allika või kandja tähenduses; taimel usuti olevat koletiste vastane vägi (unhuldenkerz; Fischer 1929; Marzell 1943-1979, Verbascum: 1023-1042). Selle kõrval kujutatud rukkilille (Centaurea cyanus L.) keskaegsete nimede seas on 'vilja õis' (korenblume, flores frumentorum; Fischer 1929); Lõuna-Aasiast pärit lõhnavate mustade seemnetega kultuurtaime musta köömet (Nigella sativa L.) nimetati nimedega 'väljaköömen', 'mustköömen', 'must õis', 'must koriander' (veltcumin, swarzkumel, melanthion, Schwartzer Coriander; Fischer 1929; Marzell 1943-1979, N. sativa: 325-327). Kummeli sarnast taimekujutist võib määratleda kui teekummelit (Chamomilla recutita (L.) Rauschert) ehk 'naistelille' (frawenblume; Fischer 1929: 274), aga ka kesalille (Matricaria perforata L.) ehk 'koeralille' ja 'koerarahu' (hundesblumen, hundestille; Fischer 1929: 274). Pildil kujutatatud liblikõieline niidu-aspar- 


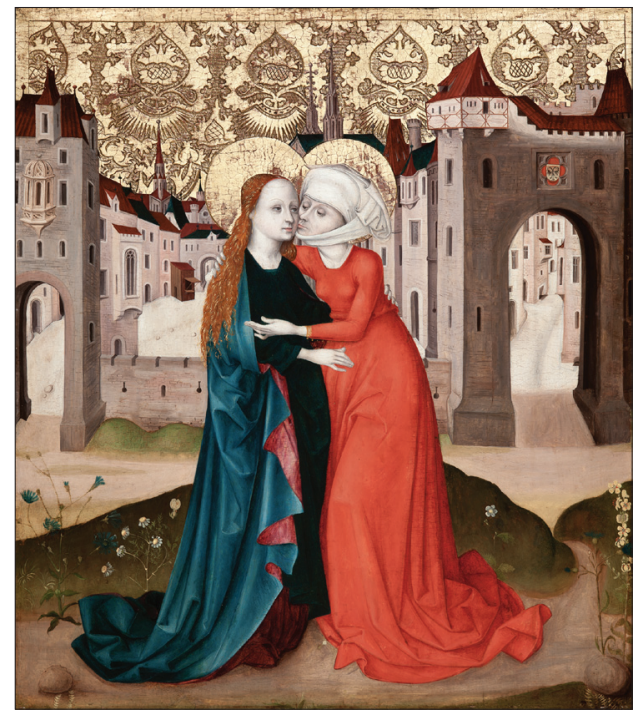

Pilt 5. a- "Maarja külaskäik Eliisabeti juurde", enne aastat 1500, tundmatu meister, Viin (000414); b-fragment taimedega: harilik sigur, teekummel/kesalill, niidu-asparhernes.

hernes (Tetragonolobus maritimus (L.) Roth) võis kunstniku ja vaataja silmis olla (nagu teised nõiahamba perekonda

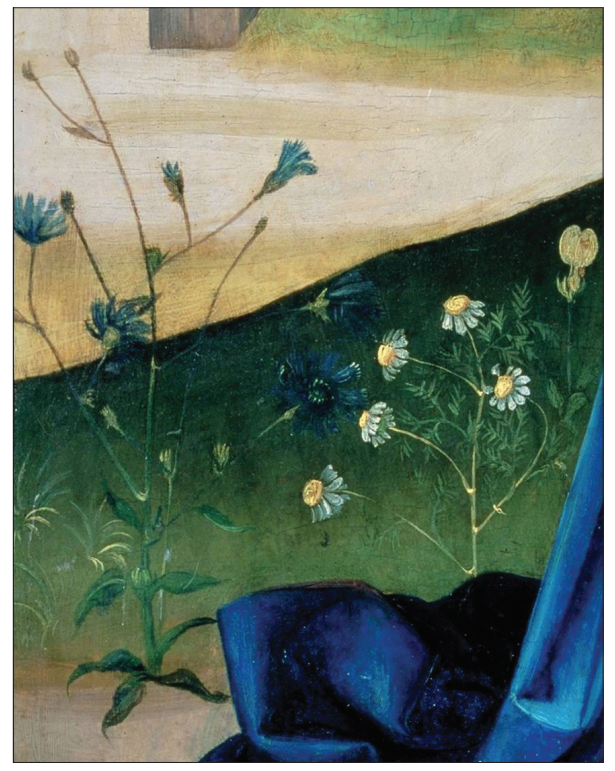
kuuluvad taimed) üks 'inglivõtmelille-

ke' (angelschlusselpluemel; Fischer 1929: 274). Ülalnimetatud taimi seob lisaks pildi teemasse sobivusele maastikuline sesoonsus: nad õitsevad suvel, sealhulgas hiliskeskajal 2. juulil tähistatud Maarja külaskäigu (Visitatio Mariae, Lk 1:39-56) kirikupüha aegu.

Maamõõla (Geum urbanum L.) ja keraheina (Dactylis glomerata L.) on kujutatud taraga ümbritsetud rohumaal stseenis, kus püha Bernhard ajab naisest välja deemonit (ca 1500, tundmatu meister, Alam-Austria; nr 000403). Mõlemad taimed on iseloomulikud pildil kujutatud maastikule - rohumaale, aasale. Vitus Auslasser nimetab maamõõla taime punaka vürtsnelgi taoliselt lõhnava juure tõttu 'õnnistatud rubiiniks' (benedicta rubea, Mayer \& Goehl et al. 2009). Saksakeelses rohuraamatus Gart der Gesuntheit aastast 1485 kirjeldatakse 'õnnisjuure' (benedictenwortz) nime all maamõõla tõrjemaagilisi omadusi: aias kasvades hoidvat taim koledad (mürgised) loomad sellest nii kaugel kui tema lõhna tunda on (Mayer \& Goehl et al. 2009). Maastikulise konteksti looduslike taimede retoorikat võib leida ka ikoonitaolistel pühendumuslikel piltidel. Nii 
näiteks hoiab Neitsi Maarja püha Anna kolmainu pildil (1460-1470, tundmatu meister, Steiermark/Kärnten; nr 000892) käes kolmeharulise varrega õitsvat peetrilehte (Succisa pratensis Moench). Kolmetine vars on andnud alust erinevate taimede kolmainuga seostavatele nimedele ja uskumusele. Ilmselt seetõttu on harilik keelikurohi ehk 'kolmis-ohakas' ja 'naisteohakas' (Dreydistel, Frauendistel) kuulunud Maarja taevaminemispüha õnnistatud taimekimpu (vt eespoolt; Marzell 1965; vt ka Sillasoo 2009; Łuczaj 2011), samuti nagu raudürt (Verbena officinalis L.) ehk 'püha rohi' (herba sacra, Fischer 1929: 288), millele omistati tõrjemaagilisi omadusi (Vogt 1893; Hertel 1901; verbena'd olid antiikajal oksad, mida kasutati pühade toimingute läbiviimisel, Marzell 1943-1979, Verbena officinalis: 1045-1046; Marzell 1926/27). Raudürti on kujutatud ühel Alam-Austriast pärit altarimaalil püha Sebastiani märtrisurma stseenis (enne 1500, tundmatu meister; nr 000752) kõrvuti harilikust sigurist ja kerarapuntslist kombineeritud taimekujutise ning nurmenukkudega. Ülalmainitud harilikku keelikurohtu ja peetrilehte seob sesoonsus: nad õitsevad augustikuistes Maarja taevaminemispüha maastikes. Peetrilehe hiliskeskaegset nime 'kuradiärahammustus' (Teufelabbi $\beta$ ) selgitatakse 1485. aasta rohuraamatus Gart der Gesundheit (Cuba 1485) legendiga, mille järgi olevat saatan saanud taimest suurt väge, kuni halastaja jumalaema selle temalt ära võttis. Näinud, et vägi oli kadunud, hammustanud saatan suurest vihast taime juurel tüki otsast ja nii kasvavat see tänapäevani. ${ }^{4}$ Allika kohaselt pärineb legend 4. sajandil muistses Kreeka linnas Pergamonis (tänapäeval Türgis) elanud arst Oribasiuselt (Marzell 1955). Peetrilehe juureks on risoom, mis taime väljatõmbamisel maast katkeb. 'Kuradi-ärahammustuseks' nimetati 16. sajandil Austrias veel käoking-tulikat (Ranunculus aconitifolius L.; Marzell 1955), mida on kujutatud varem mainitud püha Valentini märtristseenis (nr 002763) kõrvuti laialehise sõrmkäpa, maikellukese, metsmaasika, võilille ja teiste taimedega, mida siinkohal pikemalt ei käsitleta.

Siintoodud näitedele tuginedes võib öelda, et hiliskeskaegsete taimesümbolite retoorika näib lähtuvat taime välimusest ja omadustest (värv, kuju, lõhn, toime), kasvukohast (aed või mets) ja kasulikkusest (kasulikud taimed ja umbrohud), mille järgi jagati neid dualistlikult headeks ja halbadeks, jumala- ja kuraditaimedeks ning seostati evangeeliumi erinevate episoodidega (vt ka Wackernagel 1872; Awbery 1984). Üldjuhul ei ole tõenäoline, et taimi kujutati pühapiltidel eeskätt nende raviomaduste tõttu, kui pilditeema ei keskendunud haigusele (Schmitz-Cliever 1951; vrd Kühn 1948). See jätaks ehk liialt tahaplaanile kristliku narratiivi kontseptsioonipõhise kujutamise. Samas võisid taimede raviomadused olla nende tundmise esmaseks aluseks. Taimede kunstiline tähendus sõltus mitmesugustest otsestest või kaudsetest 
kultuurilistest praktikatest. Taimede sümbolism võis tublisti varieeruda, see ei huvitanud kunstnikke ühtviisi (vt Haig 1913; Koch 1964: 71; Behling 1967). Uurijate arvates võis Matthias Nethart Grünewaldile olla taim nii "loodusnähtus” kui ka sümbol, Hans Baldung Grienile deemonlikest jõududest haaratud loodusnähtus ning Albert Altdorferile ravivõimega müsteerium, sügav salajane teadmine (Behling 1967).

Rikkalikust taimekujutiste ja nende võimalike tõlgenduste valikust saab järeldada, et altarimaalidel leidus hulgaliselt sellist ideoloogiat, mis reformimeelsete teoloogide arusaamade järgi ei soodustanud kristlikku meditatsiooni, nagu väidavad kunstiuurijad (Ward 1994), vaid hajutas usklike tähelepanu. Protestantlik teoloogia ei toetanud usu mitteametlikke tõlgendusi, arendusi, ebausku ning kultuslikke praktikaid ehk nn külakatoliiklust; selle suhe rahvakultuuri ja rahvausku oli hävitav (vt Burke 2006). Väidetavalt ei tohtinud kristlikus kunstis pärast 16. sajandit maasikakujundit kasutada (vt Erdbeere, Kirschbaum 1994). Reformatsioonieelse kunsti teemadest ligi poole moodustasid kultuslikud Neitsi Maarja ja pühakute elu ning märterluse stseenid, kus maastikke taimedega sageli kujutati (vrd Christensen 1979: 207). Sedalaadi piltide keelustamine ja hävitamine tõi endaga kaasa vastava pilditraditsiooni katkemise. Paikkonnis, kus reformatsiooniga ei kaasnenud pildirüüstet, näiteks Nürnbergis, kultuslikud religioosse sisuga maalid küll säilisid, kuid nende religioosne tähendus muutus. Maapiirkondades, mis jäid väljapoole kirikuvõimu esindajate tähelepanu, võis religioosne kunst, samuti traditsioonilised uskumused ja praktikad, püsida pikemalt (vt Heal 2002). Hiliskeskajale omane rahvalik mõtlemisviis varauusajal ei kadunud, kuid reformatsiooniga piirati selle levimis- ja avaldumisvorme (Burke 2006; Scribner 2001). Looduse ja taimede kujutamine kandus ilmalikesse žanritesse, sh maastikumaalid ja natüürmordid. Maalikunstile jäi tema representatiivne funktsioon, kuid sellega seoses peamiselt kultuurtaimede kujutamine (Moggi 1987).

\section{Kokkuvõte}

Mõistagi ei olnud taimede kujutamine sakraalse kunsti põhieesmärk, vaid need kuulusid loomuliku osana pildi loodusmaastike juurde. Kujutatud taimede valik ja kontekstiline tähendusloome sõltus enim kunstnike ja nende patroonide teadmistest ja kogemustest. Vaatajal oli seda suurem roll, mida lähemalt ta kujutisi nägi ja vastavalt oma arusaamale tõlgendas, nii nagu tehti käesolevas uurimuses. (Antud käsitluse puhul tuleb silmas pidada, et tegemist oli uurija 
käsutuses olnud andmebaasiga, mitte ühes kirikus eksponeeritud pühapiltidega, mida oli võimalik pikema aja jooksul lähemalt vaadelda.) Valikusse võis sattuda taimi, mida enda ümber nähti koduõues ja teeservas, taimi, mis kandsid endas sotsiaalse kuuluvuse tunnuseid ja (materiaalseid) väärtusi, näiteks aialilled, ning taimi, mis sobisid pildi narratiivi metafooride ja allegooriatena, laenatuna teistest töödest, rahvapoeesiast ja kirjasõnast, hiliskeskaegsetest taimi käsitletavatest teostest. Sel perioodil, mil suurenes vernakulaarse kirjanduse osatähtsus üldiselt, ilmus järjest enam kodukeelseid rohuraamatuid, kuhu klassikaliste autorite kirjaliku traditsiooni kõrval talletati uuemat, kohalikku suulist pärimust. Rohuraamatud on peaaegu ainuke allikas, mis sisaldab informatsiooni suure hulga looduslike taimede kohta nõnda, et taimi on võimalik reaalselt ära tunda. Tekstides pole see täpsema kirjelduse ja illustratsiooni puudumisel tihti võimalik. Hiliskeskaegsetes ja varauusaegsetes botaanilistes töödes leiduvate taimenimede mitmekesisus ja nende varieerumine annab kristlikus kunstis kujutatud taimede tõlgendamiseks avarad võimalused. Looduslike taimede, samuti nagu paljude teiste materiaalse maailma objektide kujutamist reformatsioonieelses kunstis võib tõlgendada kristluse, rahvausu ja traditsioonilise igapäevaelu kokkukuuluvuse väljendusena. Reformatsiooni tõttu teatud tüüpi kultuslike pühapiltide kõrvaleheitmisega kadus sakraalsest ruumist keskkonda ja loodust kaasav narratiiv ühes suure hulga looduses kasvavate taimede kujutistega.

\section{Tänuavaldused}

Südamlik tänu Salzburgi Ülikooli keskaja ja varase uusaja materiaalse kultuuri instituudile Kremsis (Institut für Realienkunde des Mittelalters und der frühen Neuzeit, Krems an der Donau) artiklis kasutatud fotode eest, ning maalide omanikele Schottenstift Wien (pildid 1-3), Moravská galerie v Brně (pilt 4) ja Kunstsammlungen Augustiner-Chorherrenstift St. Florian (pilt 5).

\section{Kommentaarid}

1 Artikkel on valminud sihtfinantseeritava teema SF0130033s07 "Maastikupraktika- ja pärand" raames ja Euroopa Liidu Regionaalarengu Fondi (Kultuuriteooria tippkeskus, CECT) toetusel.

${ }^{2}$ Keskajal populaarsed, tavaliselt illustreeritud ja õpetliku alatooniga lugude kogumikud metsloomadest ja -lindudest. 
3 Sarnaste nimedega tuntakse seda taime meilgi (Vilberg 1933; Vilbaste 1993).

4 Taime eestikeelne nimi peetrileht on seotud sarnase legendiga (Vilbaste 1993); Marzelli (1955) arvates toimus nimede muutus (kuradi asemele tuli Peetrus) seetõttu, et Põhjamaades tõlgendati saatanat piksejumal Thorina, mis muutus eesti pärimuses Peetruseks.

\section{Kirjandus}

Arber, Agnes Robertson 1912. Herbals: Their Origin and Evolution: A Chapter in the History of Botany, 1470-1670. Cambridge: Cambridge University Press.

Awbery, Gwen M. 1984. Plant names of religious origin in Welsh oral tradition. Vickery, Roy (toim). Plant-lore studies: papers read at a joint conference of the Botanical Society of thr Britisch Isles and the Folklore Society, held at the University of Sussex, April 1983. The Folklore Society Mistletoe Series 18. London: University College London, lk 1-9.

Bauhin, Johannes 1591. De Plantis a Divis Sanctisve nomen habentibus: Caput ex magno volumine de consensu \& dissensu authorum circa stirpes, desumptum. Basel: Conrad Waldkirch.

Behling, Lottlisa 1967. Die Pflanze in der mittelalterlichen Tafelmalerei. Köln: Böhlau Verlag.

Burke, Peter 2006 [1978]. Popular Culture in Early Modern Europe. Ashgate Publishing. Burke, Peter 2008. Eyewitnessing: The Uses of Images As Historical Evidence. Cornell University Press.

Bächtold-Stäubli, Hanna \& Hoffmann-Krayer, Eduard (toim) 1987. Handwörterbuch des deutschen Aberglaubens. Berlin: Walter de Gruyter.

Christensen, Carl C. 1979. Art and the Reformation in Germany. Ohio: Athens.

Cohen, Simona 2008. Animals as diguised symbols in Renaissance art. Brill's Studies in Intellectual History. Vol. II. Leiden: Brill.

Cuba, Johannes de [Johann Wonnecke von Kaub] 1485. Gart der Gesundheit. Mainz: Peter Schoeffer.

Egg, Erich \& Pfaundler, Wolfgang 1985. Gotik in Tirol: die Flügelaltäre. Innsbruck: Haymon-Verlag.

Fischer, Hermann 1929. Mittelalterliche Pflanzenkunde. Munich: Verlag der Müncher Drucke.

Gago, P. \& Santiago, J. L. \& Boso, S. \& Alonso-Villaverde, V. \& Martinez, M. C. 2009. Grapevine (Vitis vinifera L.): Old Varieties are Reflected in Works of Art. Economic botany 63 (1), lk 67-77 (doi: 10.1007/s12231-008-9059-y).

Haig, Elizabeth 1913. The Floral Symbolism of the Great Masters. New York: Dutton $\&$ Co.

Harbison, Craig 2002. Renessansskunst põhja pool Alpe. Järv, Ingrid (tlk). Tallinn: Kunst. 
Heal, Bridget 2002. Images of the Virgin Mary and Marian devotion in Protestant Nuremberg. Parish, Helen, L. \& Naphy, William G. (toim). Religion and superstition in Reformation Europe. Manchester: Manchester University Press, lk 25-46.

Hegi, Gustav 1922. Alpenflora, die verbreitetsten Alpenpflanzen von Bayern, Österreich und der Schweiz. München: Lehmann.

Hertel, Gustav 1901. Aberglaubische Gebräuche aus dem Mittelalter. Zeitschrift des Vereins für Volkskunde, lk 272-279.

Huizinga, Johan 1996 [1924]. The Autumn of the Middle Ages. Chicago: The University of Chicago Press.

Janick, Jules \& Paris, Harry S. \& Parrish, David C. 2007. The cucurbits of mediterranean antiquity: Identification of taxa from ancient images and descriptions. Annals of Botany 100 (7), lk 1441-1457 (doi: 10.1093/aob/mcm242).

Kirschbaum, Engelbert (toim) 1994. Lexicon der Christlichen Ikonographie. Rome: Herder.

Koch, Robert A. 1964. Flower symbolism in the Portinari altar. The Art Bulletin 46 (1), lk 70-77.

Krausch, Heinz-Dieter 2007. 'Kaiserkron und Päonien rot ...'Von der Entdeckung und Einführung unserer Gartenblumen. Reprint. München: Deutscher Taschenbuch Verlag.

Kühn, Wolfgang 1948. Grünewalds Isenheimer Altar als Darstellung mittelalterlicher Heilkräuter. Kosmos: Handweiser für Naturfreunde 44 (12), lk 327-333 (http://www. joerg-sieger.de/isenheim/texte/hinweis/i_10fa.htm\#oben - 4. november 2013).

Łuczaj, Łukasz 2011. Changes in Assumption Day Herbal Bouquets in Poland: A Nineteenth Century Study Revisited 1. Economic Botany 65 (1), lk 66-75 (doi: 10.1007/ s12231-011-9148-1).

Löber, Karl 1988. Agaleia. Erscheinung und Bedeutung der Akelei in der mittelalterlichen Kunst. Köln: Böhlau.

Marzell, Heinrich 1926/1927. Das Eisenkraut (Verbena officinalis) als Zauberpflanze. Der Naturforscher 3, lk 419-425.

Marzell, Heinrich 1955. Teufelskräuter. Bayerisches Jahrbuch für Volkskunde. Regensburg: Verlag Josef Habbel, lk 211-215.

Marzell, Heinrich 1960. Passionsblumen. Ein botanischer Beitrag zur religiösen Volkskunde. Bayerisches Jahrbuch für Volkskunde. München: Der Bayerischen Landesstelle für Volkskunde, lk 159-162.

Marzell, Heinrich 1962. Hexen un Druden in deutschen Pflanzennamen. Bayerisches Jahrbuch für Volkskunde. Würzburg: Kommissionverlag Karl Hart, lk 107-115.

Marzell, Heinrich 1965. Die Ebe rwurtz (Carlina) im Brauchtum und in der Volksmedizin. Bayerisches Jahrbuch für Volkskunde 1964/65. Würzburg: Hart, lk 7-13.

Marzell, Heinrich 1943-1979. Wörterbuch der deutschen Pflanzennamen 1-5. Leipzig: Verlag von S. Hirtel. 
Mayer, Johannes Gottfried \& Goehl, Konrad \& Englert, Katharina 2009. Die Pflanzen der Klostermedizin in Darstellung und Anwendung: mit Pflanzenbildern des benediktiners Vitus Auslasser (15. Jh.) aus dem Clm 5905 der bayerischen Stastsbibliothek München. Baden-Baden: Deutscher Wissenschafts-Verlag.

Moggi, Guido 1987. Le piante nella pittura italiana dei secoli XV e XVI: problemi e metodi di identificazione botanica. Prinz, Wolfram \& Beyer, Andreas (toim). Die Kunst und das Studium der Natur vom 14. zum 16. Jahrhundert. Weinheim: Acta humaniora, lk 61-74.

Panofsky, Erwin 1971. Early Netherlandish Painting, Its Origin and Character 1. New York: Icon Editions.

Paris, Harry S., Janick, Jules \& Daunay, Marie-Christine 2011. Medieval herbal iconography and lexicography of Cucumis (cucumber and melon, Cucurbitaceae) in the Occident, 1300-1458. Annals of Botany 108 (3), lk 471-484 (doi: 10.1093/aob/mcr182).

Pfeiffer, Franz (koost) 1862-1880. Berthold von Regensburg: vollständige Ausgabe seiner Predigten mit Ammerkungen und Wörterbuch. Wien: Wilhelm Braumüller.

Pfeiffer, Franz (toim) 1861. Das Buch der Natur von Konrad von Megenberg. Die erste Naturgeschichte in deutscher Sprache. Stuttgart: Verlag Karl Aue.

Réau, Louis 1996. Iconografía del Arte Cristiano. Iconografía de la Biblia. Antiguo Testamento. Kd 1. Barcelona: Ediciones del Serbal.

Reeds, Karen Meier 1991. Botany in Medieval and Renaissance Universities. New York: Garland Publications.

Reinitzer, Heimo 1982. Der verschlossene Garten: Der Garten Marias im Mittelalter. Wolfenbüttel: Herzog Augusst Bibliothek.

Russell, Jeffrey Burton 1992. Lucifer: The Devil In The Middle Ages. Ithaca: Cornell University Press.

Salzer, Anselm 1893. Die Sinnbilder und Beiworte Mariens in der deutschen Literatur und lateinischen Hymnenpoesie des Mittelalters: Mit Berücksichtigung der patristischen Literatur. Linz: K. u. k. Hofbuchdruckerei Jos. Feichtingers Erben.

Schmitz-Cliever, Egon 1951. Die Darstellung der Syphilis auf dem sogenannten Aachener Altarbild der Kölner Malerschule (um 1510). Archiv für Dermatologie und Syphilis 192, lk 164-174.

Scribner, Robert W. 1994. For the sake of simple folk: popular propaganda for the German Reformation. Clarendon Paperbacks. Oxford: Oxford University Press.

Scribner, Robert W. 2001. Religion and culture in Germany (1400-1800). Studies in medieval and Reformation thought 81. Leiden: Brill.

Sillasoo, Ülle 2003. Plant depictions in late medieval religious art. Laszlovszky, József \& Szabo, Peter (toim). People and Nature in Historical Perspective. Budapest: Central European University \& Archaeolingua, lk 377-393.

Sillasoo, Ülle 2006. Medieval plant depictions as a source for archaeobotanical research. Vegetation History and Archaeobotany 16 (1), lk 61-70 (doi: 10.1007/s00334-006-0036-z). 
Sillasoo, Ülle 2009. Plants in Late Medieval festivals and customs in written and pictorial sources from southern central Europe. Environmental Archaeology 14 (1), lk 76-89 (doi: 10.1179/174963108X345720).

Ward, John L. 1994. Disguised symbolism as enactive symbolism in van Eyck's paintings. Artibus et Historiae, 15 (29), lk 9-53 (doi: 10.2307/1483484).

Vavra, Elisabeth 1980. Kunstwerke als Quellenmaterial der Sachkulturforschung. Europäische Sachkultur des Mittelalters. Veröffentlichungen des Instituts für Mittelalerliche Realienkunde Österreichs 4. Wien: Verl. d. Österr. Akad. d. Wiss, lk 195-232.

Vilberg, Gustav 1933. Eestikeelsetest taimenimedest ja nende tekkimisvõimalusist: nurmenuku nimesid Eestis. Tartu: Postimees.

Vilbaste, Gustav 1933. Eesti taimenimetused = Nomina vernacula plantarum Estoniae . Tallinn: Eesti Teaduste Akadeemia.

Vogt, Friedrich 1893. Beiträge zur deutschen Volkskunde aus älteren Quellen. Zeitschrift des Vereins für Volkskunde, lk 349-372.

Voragine, Jacobus de 1993. The Golden Legend: Reading on the Saints. Kd. 1-2. Ryan, William Granger (tlk). Princeton, N.J.: Princeton University Press.

Wackernagel, Wilhelm 1872. Farben- und Blumensprache des Mittelalters. Wackernagel, Wilhelm (toim). Kleinere Schriften 1: Abhandlungen zur deutschen Alterthumskunde und Kunstgeschichte. Leipzig: Hirzel, lk 143-240.

Waterworth, J. (toim ja tlk) 1848. The canons and decrees of the sacred and oecumenical council of Trent. London: Dolman (http://history.hanover.edu/texts/trent.html - 8. november 2013).

Winston-Allen, Anne 1998. Stories of the Rose: The Making of the Rosary in the Middle Ages. University Park: The Pennsylvania State University Press.

\section{Summary}

\section{Keys of Heaven and Hands of Christ: Plants in Pre-Reformation Art in Southern Central Europe}

\section{Ülle Sillasoo}

Keywords: religious art, landscapes, flowering plants, plant names

One of the characteristics of the 15th-16th-century pre-Reformation sacral art in southern central Europe, as well as in the Netherlands and Italy, is the multitude of natural plant depictions. Depending on the artists and subjects of paintings, plant depictions could, similarly to animal depictions, fulfil the roles of attributes, allegorical and metaphorical devices and/or to represent various landscapes. The appearance and properties of plants, their habitats and usage are the fundamental features of plant symbolism. 
Plant names in late medieval and early modern period herbals is another important clue for understanding the meaning of vegetation shown in the context of landscapes. Natural plants in pre-Reformation art, as interpreted here, represent the syncretism of Christian and folk belief in mundane and spiritual life. The richness of popular elements in Christian art and their interpretation, however, was a reason for the discontinuation of the same pictorial tradition and its replacement by another, suppressed into institutional frames and more controlled by the authorities. 